\begin{tabular}{|c|c|c|}
\hline $\begin{array}{c}\text { OPEN } \\
\text { JOURNAL } \\
\text { SYSTEMS } \\
\end{array}$ & $\begin{array}{l}\text { Available on line at Directory of Open Access Journals } \\
\text { Journal of Hyperspectral Remote Sensing v.10, n.1 (2020) } 1-9\end{array}$ & $\begin{array}{c}\text { Journal of } \\
\text { Hyperspectral } \\
\text { Remote Sensing } \\
\end{array}$ \\
\hline ISSN:2237-2202 & & www.ufpe.br/jhrs \\
\hline
\end{tabular}

\title{
Persistent Scatterer Interferometry of Sentinel-1 time series to detect ground subsidence in the city of Recife, Brazil
}

\author{
Enton Bedini* \\ ${ }^{*}$ Geological Institute, Tirana, Albania. International Institute of Geo-information Science and Earth Observation (ITC), Enschede, \\ The Netherlands. Email: enton_bedini@ hotmail.com. (Corresponding author).
}

Received 13 January 2020; accepted 31 March 2020

\begin{abstract}
Persistent Scatterer Interferometry (PSI) analysis of Sentinel-1 time series was carried out to detect ground subsidence in the city of Recife, Brazil. The dataset consisted of sixty-eight Sentinel-1A Interferometric Wide (IW) Single Look Complex (SLC) images of the time period April 2017 - September 2019. The images were acquired in descending orbit in VV (vertical transmitting, vertical receiving) polarization. The results of the PSI analysis show that in the city of Recife occur several ground subsidence areas. The largest ground subsidence area occurs between the neighborhoods of Afogados, Torrǒes and Cordeiro. The subsidence rates in this area range from few mm/year up to -15 $\mathrm{mm} /$ year. This ground subsidence could be a result of groundwater extraction or of subsidence processes in urbanized reclaimed lands. Similar but smaller ground subsidence areas occur in several localities in Recife. In some cases, subsidence with rates of up to $-25 \mathrm{~mm} /$ year is noted in small zones where new buildings have been constructed in the last decade. This should be due to ground settlement processes, taking a long time due to the particular soils and geology of the locality. This study can serve as a first contribution for further research on the ground subsidence hazard in the city of Recife and the surrounding areas by means of satellite radar imagery.
\end{abstract}

Keywords: Sentinel-1, land subsidence, Persistent Scatterer Interferometry, estuarine area, Recife.

\section{Introduction}

The city of Recife is the capital of the state of Pernambuco in Brazil. Recife is built on the estuarine area of Capibaribe River (Figure 1). Recife has been developed through the last five centuries, with large areas of land reclamation from stream reaches, wetland and mangroves (Cabral et al., 2008). The rapid urban development in the last fifty years has put pressure on the groundwater resources of the area. To address the necessity of a sustainable management of the groundwater resources the municipality of Recife has enforced regulations on groundwater pumping and the use of old and new wells (Costa et al., 1998). The excessive groundwater exploitation especially during drought periods creates both actual and potential problems of lowering groundwater levels, water quality degradation, salinization and risk of land subsidence (Cabral et al., 2008). The rapid urban development on an estuarine area and the lowering of the groundwater table are both factors that can cause ground subsidence (e.g., Cui, 2018).
The Sentinel-1 Synthetic Aperture Radar (SAR) mission of the European Space Agency (ESA) has brought new possibilities for the application of satellite radar imagery to geosciences (e.g., Sowter et al., 2016; Yagüe-Martínez et al., 2016; Zhou et al., 2017; Budillon et al., 2018; Kalia, 2018; Bedini, 2019; Delgado Blasco et al., 2019). It consists of identical sensors mounted on the Sentinel-1A satellite (launched into orbit in April 2014), and on the Sentinel 1B satellite (launched into orbit in April 2016) that record C-band $(5.3 \mathrm{~cm})$ SAR imagery (Torres et al., 2012). The revisiting time of an area is twelve days for each satellite. The Persistent Scatterer Interferometry (PSI) analyses of time-series of SAR images (Ferretti et al., 2001) provides millimeter-scale detection of the ground motion. The use of the time-series of SAR images is an important source of information for the detection, mapping and monitoring of ground subsidence, especially in the urban areas (e.g., Chen et al., 2012; Notti et al., 2016; Zhou et al., 2017; Budillon et al., 2018; Bedini, 2019; Crosetto et al., 2019). 


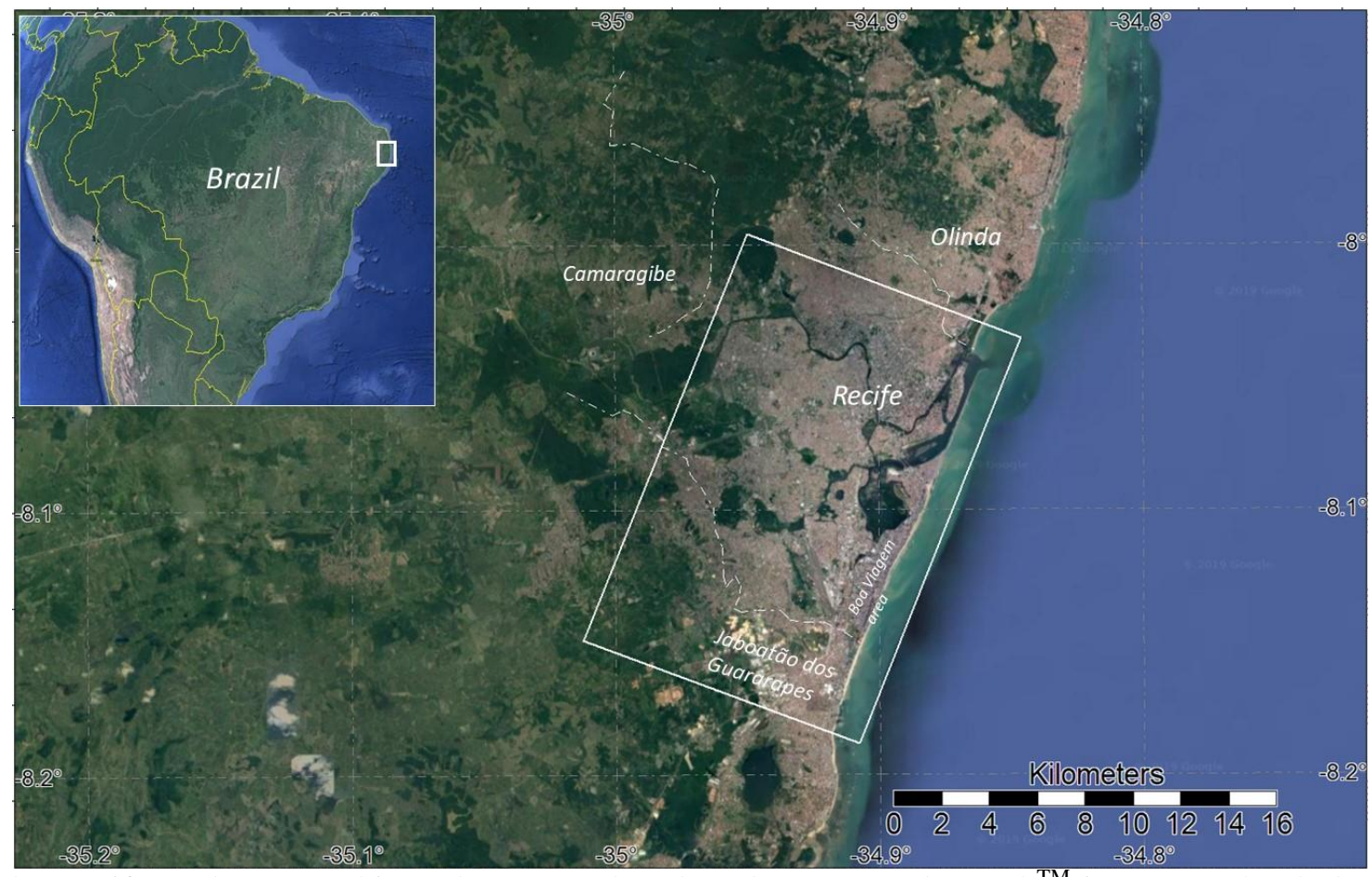

Figure 1- The Recife study area (white color rectangle) plotted onto Google Earth ${ }^{\mathrm{TM}}$ imagery. The dashed white line shows boundaries between municipalities.

Several studies have considered the ground subsidence hazard in the city of Recife (e.g., Costa et al., 2005; Luna et al., 2017; Coelho et al., 2018). However, there have not been reported studies on the use of the radar interferometry for ground subsidence detection in the city of Recife. This paper reports on the use of the Persistent Scatterer Interferometry (PSI) analysis of multi-temporal Sentinel-1 SAR images of the time period April 2017 - September 2019 to detect ground subsidence in the city of Recife, Brazil (Figure $1)$. The study area consists of 11 x $18 \mathrm{~km}$. This study can serve as a first contribution for further research on the ground subsidence hazard in the city of Recife and the surrounding areas by means of satellite radar imagery.

\section{Materials and methods}

The Sentinel-1 Single-Look Complex (SLC) SAR images are recorded using the Terrain Observation by Progressive Scans (TOPSAR) acquisition technology (Zan and Guarnieri, 2006). The Interferometric Wide swath mode (IW) is the standard mode of Sentinel-1 data acquisition. The TOPSAR technology produces SAR image data in sub-swaths. Within the sub-swath, the Sentinel-1 IW images are acquired by recording subsets of echoes of the SAR aperture, which are called bursts (e.g., Yagüe-Martínez et al., 2016). The Sentinel-1 IW images have a ground resolution of $5 \mathrm{~m} \times 20 \mathrm{~m}$, and a swath of $250 \mathrm{~km}$.

The Persistent Scatterer Interferometry (PSI), (Ferretti et al., 2001) is based on the Differential Interferometric Synthetic Aperture Radar (DInSAR) technique (e.g., Hanssen, 2001). The DInSAR uses the radar phase $(\varphi)$ of at least two SAR images of the same area, to form an interferometric pair (Crosetto et al., 2016). The change in the radar phase $(\varphi)$ at ground target $\mathrm{P}$, between the two measurements, unexplained from other factors (sensor position at times $t_{1}$ and $t_{2}$, noise, atmosphere, topography), is due to ground displacement $\left(\varphi_{\text {Displ }}\right)$ (Figure 2$)$. The DInSAR technique (e.g., Hanssen, 2001) has found applications in the fields of seismology, volcanology, glaciology, landslides, ground subsidence and uplift, etc. (e.g., Crosetto et al., 2016). In order to achieve millimeterscale detection of the ground deformation, the PSI analyzes a time series of SAR images (Ferretti et al., 2001) using the DInSAR technique. The large number of the analyzed SAR images reduces the effects of the sensor noise and atmospheric distortion to the phase component. 


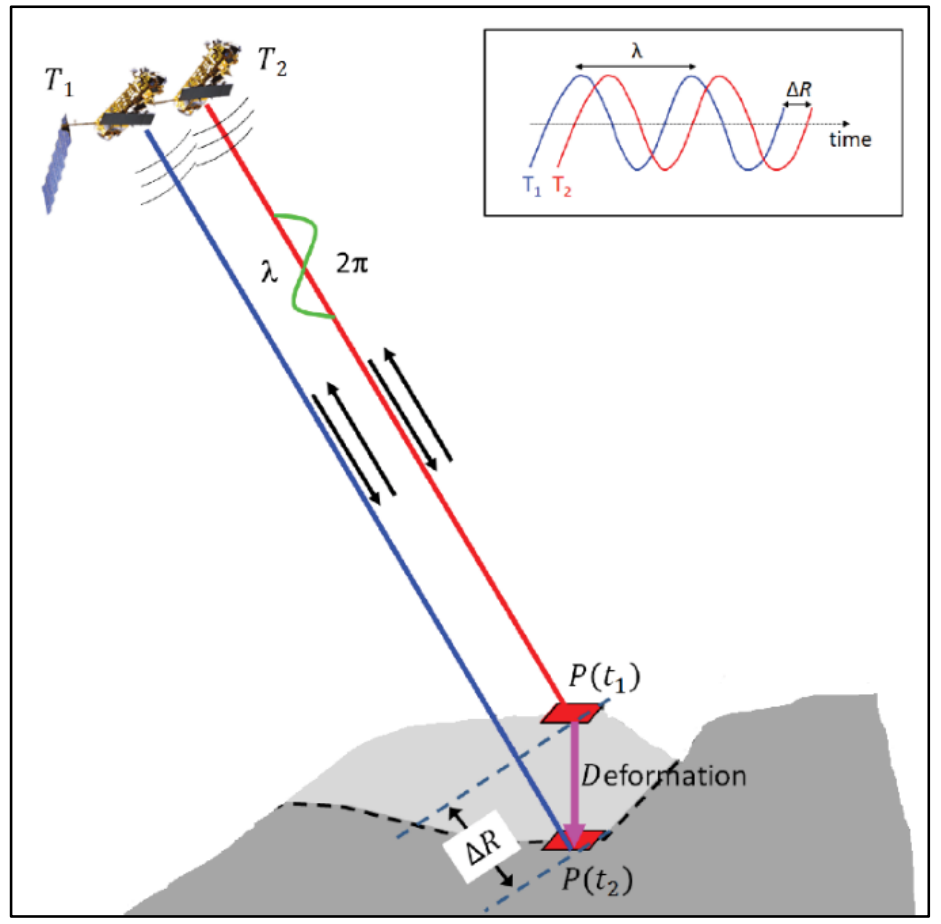

Figure 2- Schematic representation of the DInSAR basic concept. The phase difference of two radar measurements $\mathrm{T}_{1}$ and $\mathrm{T}_{2}$ of a ground target $\mathrm{P}$, recorded at time $t_{1}$ and $t_{2}$, due to a subsidence occurring within this time period at the ground target from position $\mathrm{P}\left(\mathrm{t}_{1}\right)$ to position $\mathrm{P}\left(\mathrm{t}_{2}\right)$ (modified from Sousa and Bastos, 2013).

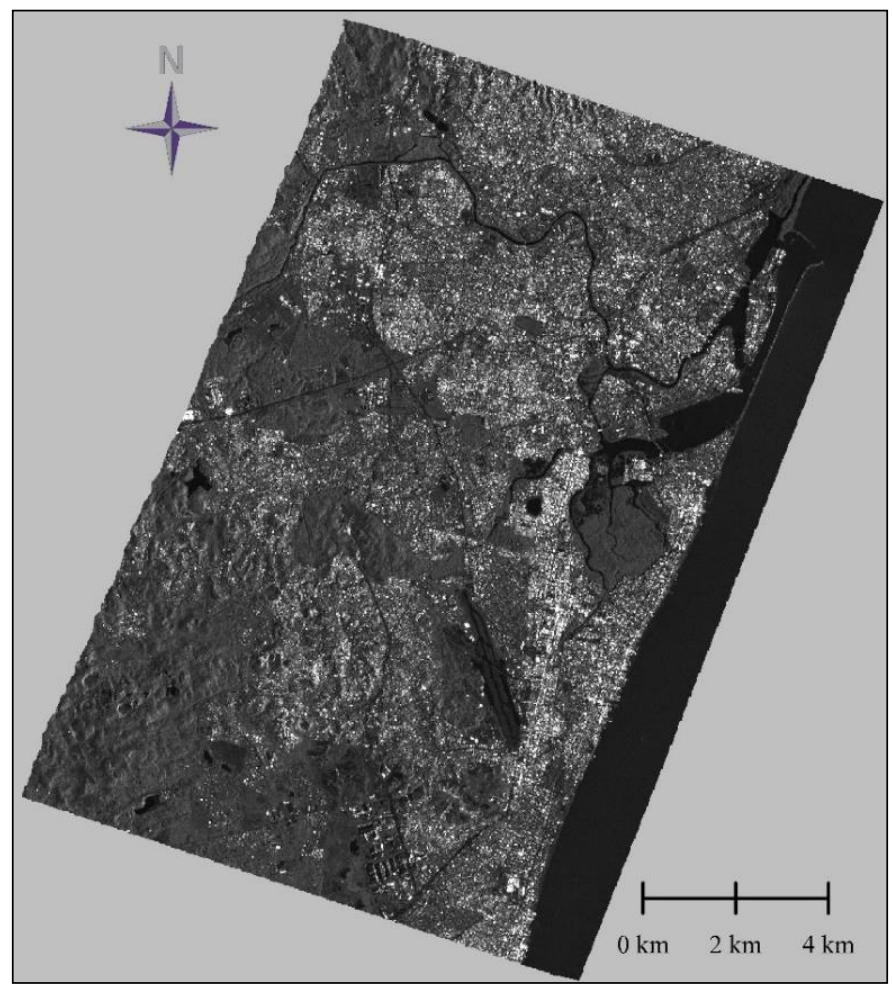

Figure 3- Geocoded Sentinel-1 image of the Recife study area, Brazil.

The Recife time series of radar imagery analyzed in this study consists of 68 Sentinel-1A IW images of the time period of April 2017 - September 2019, acquired in descending orbit 9 in VV (vertical E. Bedini / Journal of Hyperspectral Remote Sensing 10(2020) 1-9 transmitting, vertical receiving) polarization. The Sentinel-1A VV SLC images were initially de-bursted, and spatially subsetted to the extent of the Recife study area (Figures 1, 3). One of the images of the 
interferometric stack recorded on June 23, 2018 was selected as the master image. The other images were coregistered to the master image. A time-position plot of the Sentinel-1A images in relation to the master image is shown in Figure 4.

Subsequently, the differential interferograms were formed between the master and each of the other images. A Digital Elevation Model (DEM) from the SRTM mission with spatial resolution of approximately $30 \mathrm{~m}$ was used to flatten the interferograms. The resulting flattened interferograms were used as input to an inversion process to find coherent Persistent Scatterers (PS). Amplitude-based methods (Ferretti et al., 2001) analyze interferograms on a pixel-by-pixel basis to identify reliable PS in urban terrain (Lauknes et al., 2010). At these PS locations is estimated the ground deformation, as a displacement of the ground in relation to the sensor, or projected as vertical displacement.

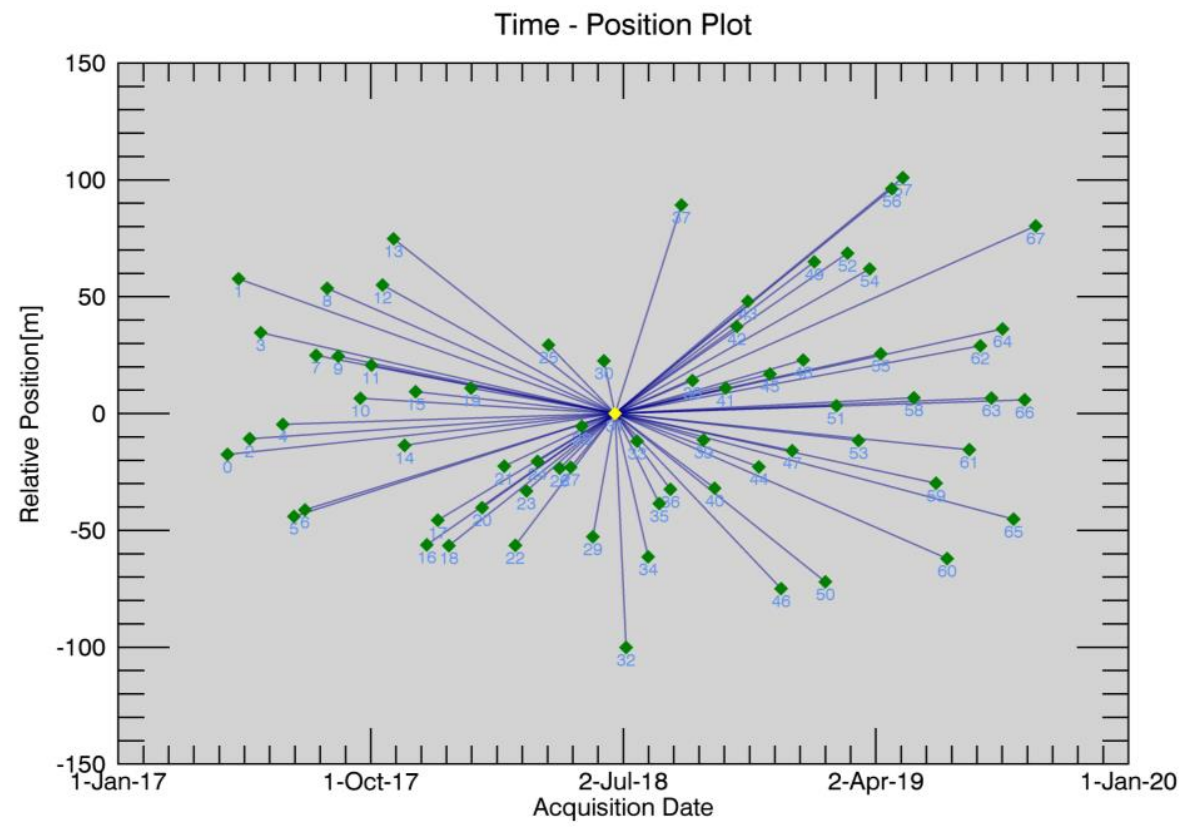

Figure 4- Graph showing the temporal and the relative position of the master image (recorded on June 23, 2018) and the other Sentinel-1A 67 images of the time period April 2017 - September 2019, used to carry out the PSI analysis of the Recife study area.

\section{Results and discussion}

The results of the PSI analysis for the city of Recife are shown in Figure 5. The PSI analysis of the Sentinel-1 data of the time period April 2017 September 2019 indicates the occurrence of ground subsidence in several areas. The largest area of ground subsidence with subsidence rates from few $\mathrm{mm} /$ year to -15 mm/year occurs between the neighborhoods of Afogados, Torrǒes and Cordeiro (Figures 5-7). The ground subsidence in this area of Recife could be due to groundwater extraction or due to subsidence processes in reclaimed lands. Another similar but smaller ground subsidence area is shown in Figure 8.

Previous reported studies that have considered ground subsidence in Recife have used geodetic techniques and focused in relatively small areas along the coast. In a study using geodetic measurements it is indicated a subsidence of $-0.68 \mathrm{~mm} /$ year in the Boa
Viagem neighborhood of Recife (Luna et al., 2017). Such low rates of subsidence may not be detectable by the PSI analysis of radar imagery due to noise in the data.

In the study area it is also detected ground sinking (with rates of up to $-25 \mathrm{~mm} /$ year) related with the construction of new buildings, a phenomenon called ground settlement in engineering geology (e.g., Waltham, 2009). Due to the particular geological and soil conditions of the Recife territory (estuarine area, reclaimed lands), the ground settlement may take long time from several to many years. For example, a small zone of ground settlement with very high rates (up to $22 \mathrm{~mm} /$ year) it is detected by the PSI analysis in the southern part of the image, in the territory of the neighboring municipality Jaboatão dos Guararapes (Figure 9). The ground settlement phenomenon occurs in the area of new buildings that were still under construction in 2009 (Figure 10). 


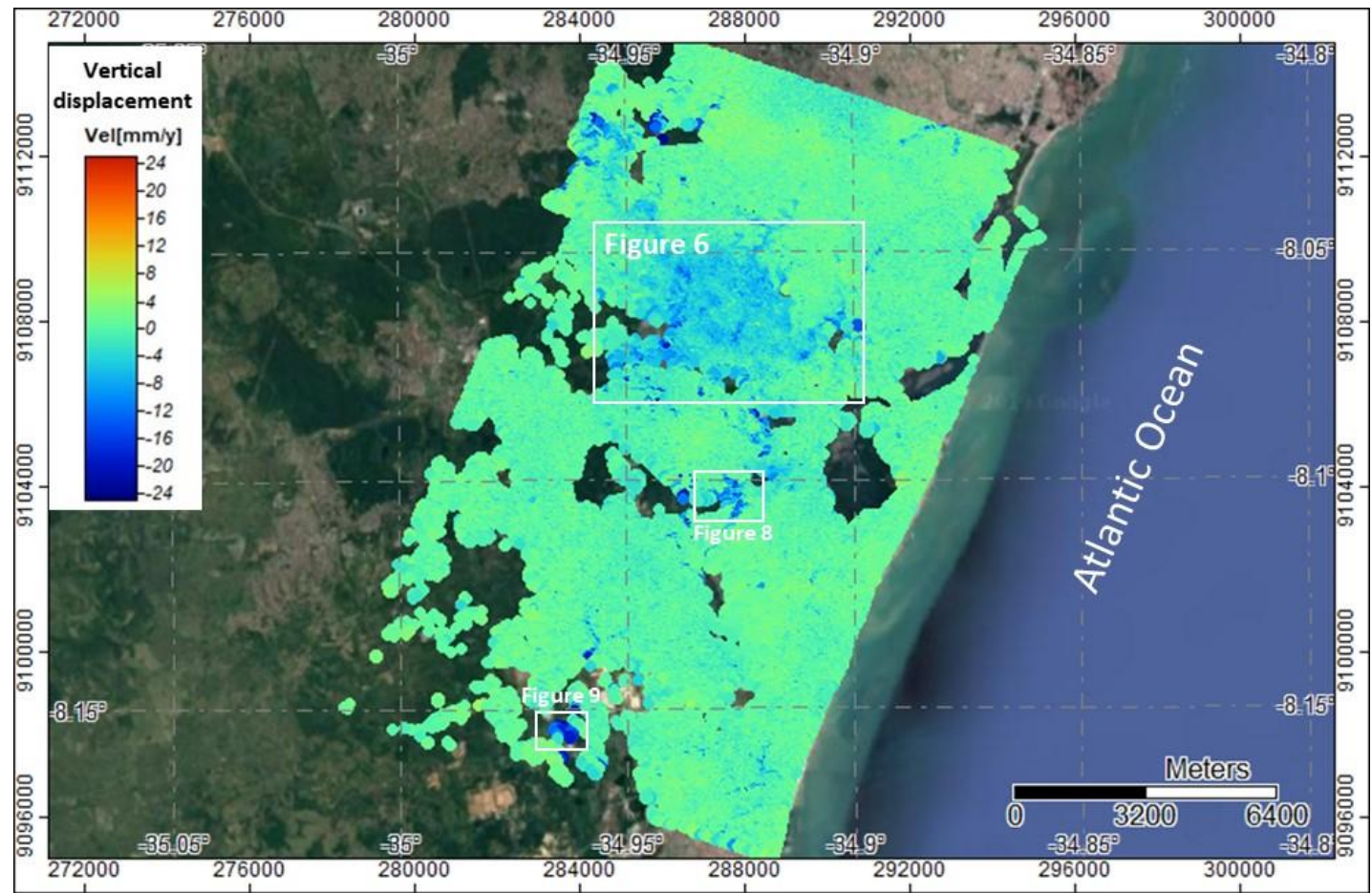

Figure 5- Results of PSI analysis of the Sentinel-1 time series of April 2017 - September 2019 of the Recife study area. The vertical ground displacement rates are shown as velocity in $\mathrm{mm} / \mathrm{year}$.

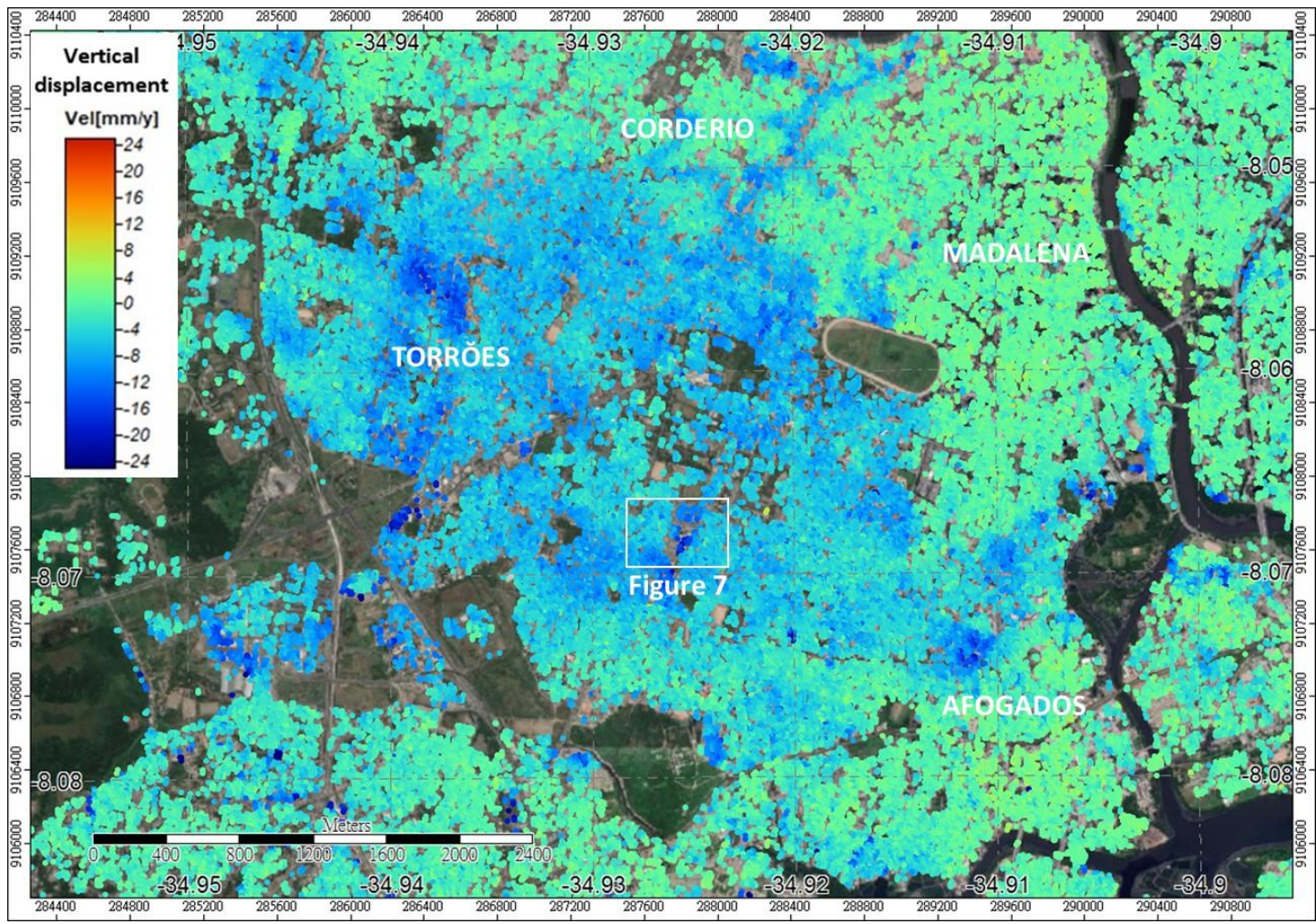

Figure 6- Large area of subsidence in Recife as detected by the PSI analysis of Sentinel-1 data of the time period April 2017 - September 2019. The vertical ground displacement rates are shown as velocity in $\mathrm{mm} /$ year. For the location see Figure 5. The background is from Google Earth ${ }^{\mathrm{TM}}$. The location of several major neighborhoods of the area are also indicated onto the map. 


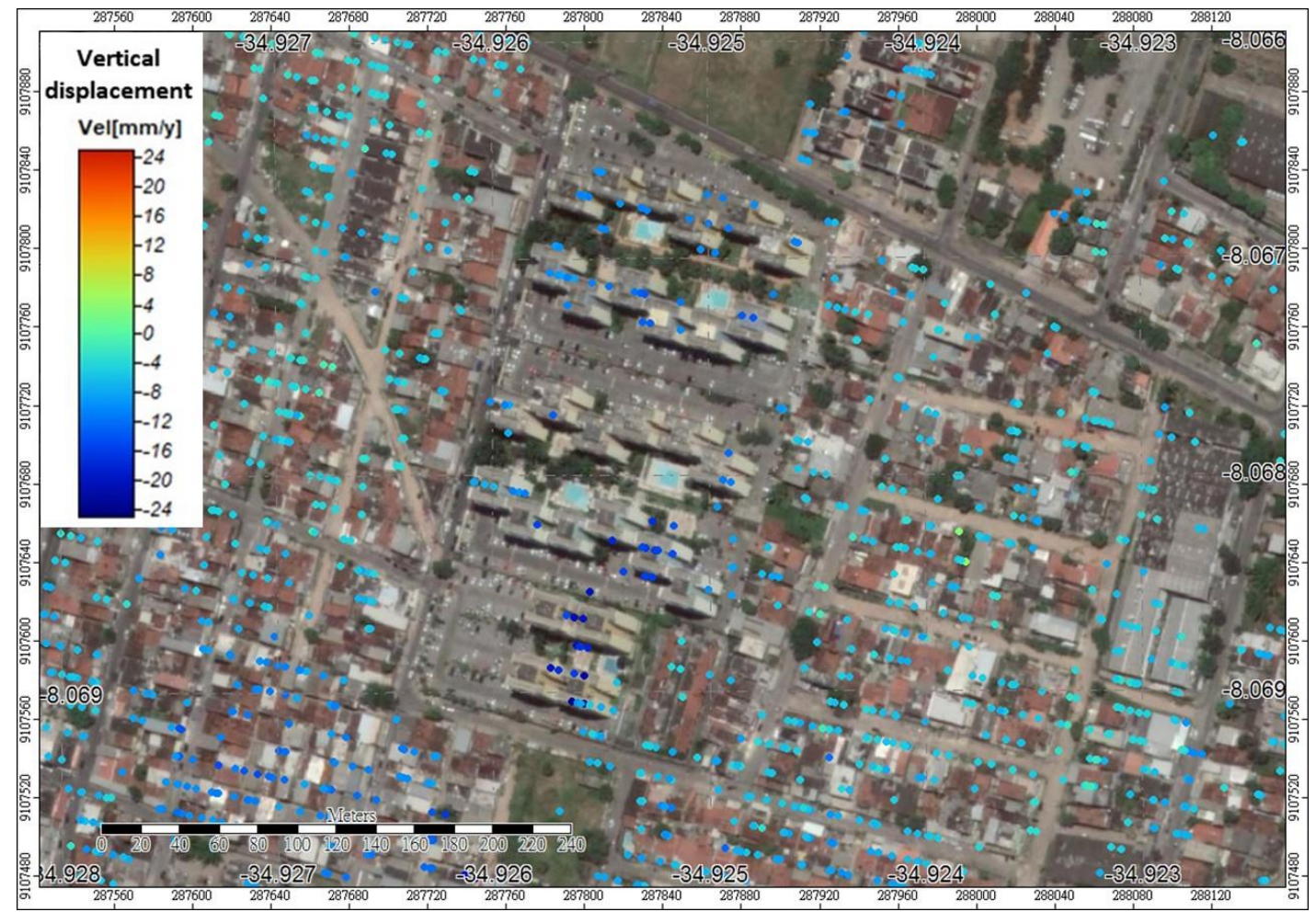

Figure 7- Close view of persistent scatterers indicating subsidence in an area of Recife. The ground displacement rates are in $\mathrm{mm} /$ year. For the location see Figure 6. The background is from Google Earth ${ }^{\mathrm{TM}}$.

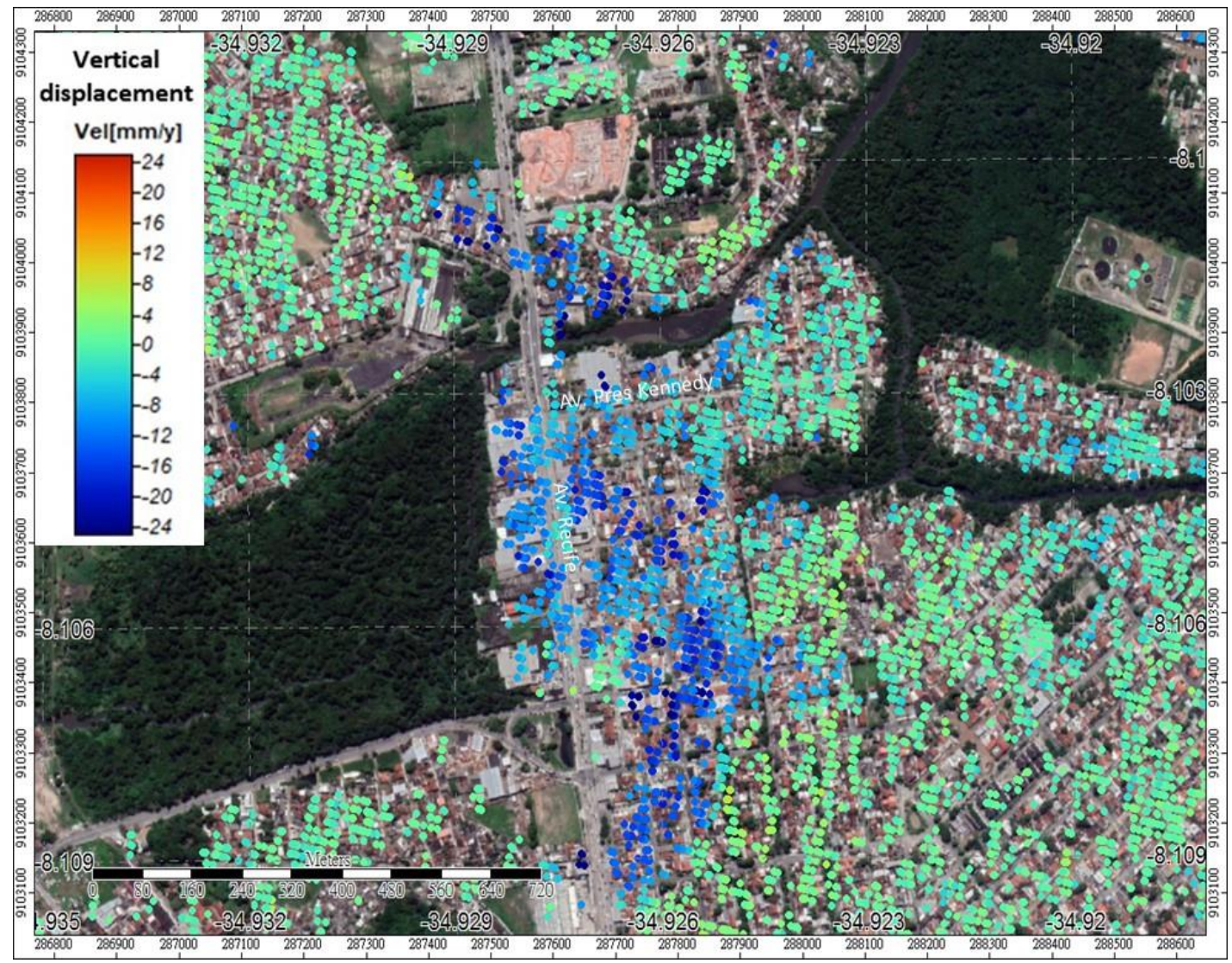

Figure 8- Close view of persistent scatterers showing subsidence in an area of Recife. The ground displacement rates are in $\mathrm{mm} /$ year. For the location see Figure 5. The background is from Google Earth ${ }^{\mathrm{TM}}$. 


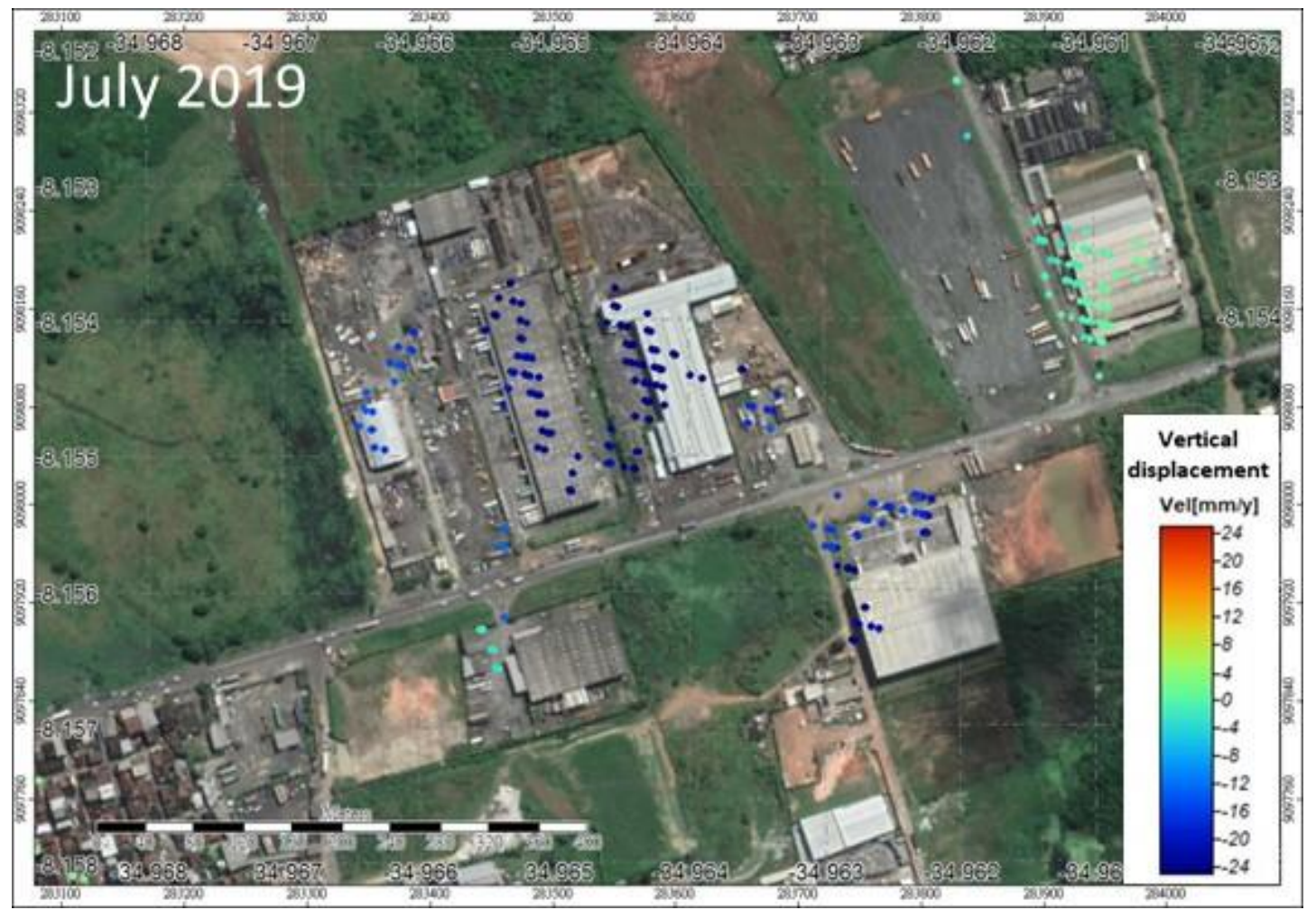

Figure 9- Close view of the PSI results in an area within Jaboatão dos Guararapes municipality showing ground settlement of up to $-22 \mathrm{~mm} /$ year of the new buildings. For the location see Figure 5. The background is from Google Earth $^{\mathrm{TM}}$ image of July 2019.

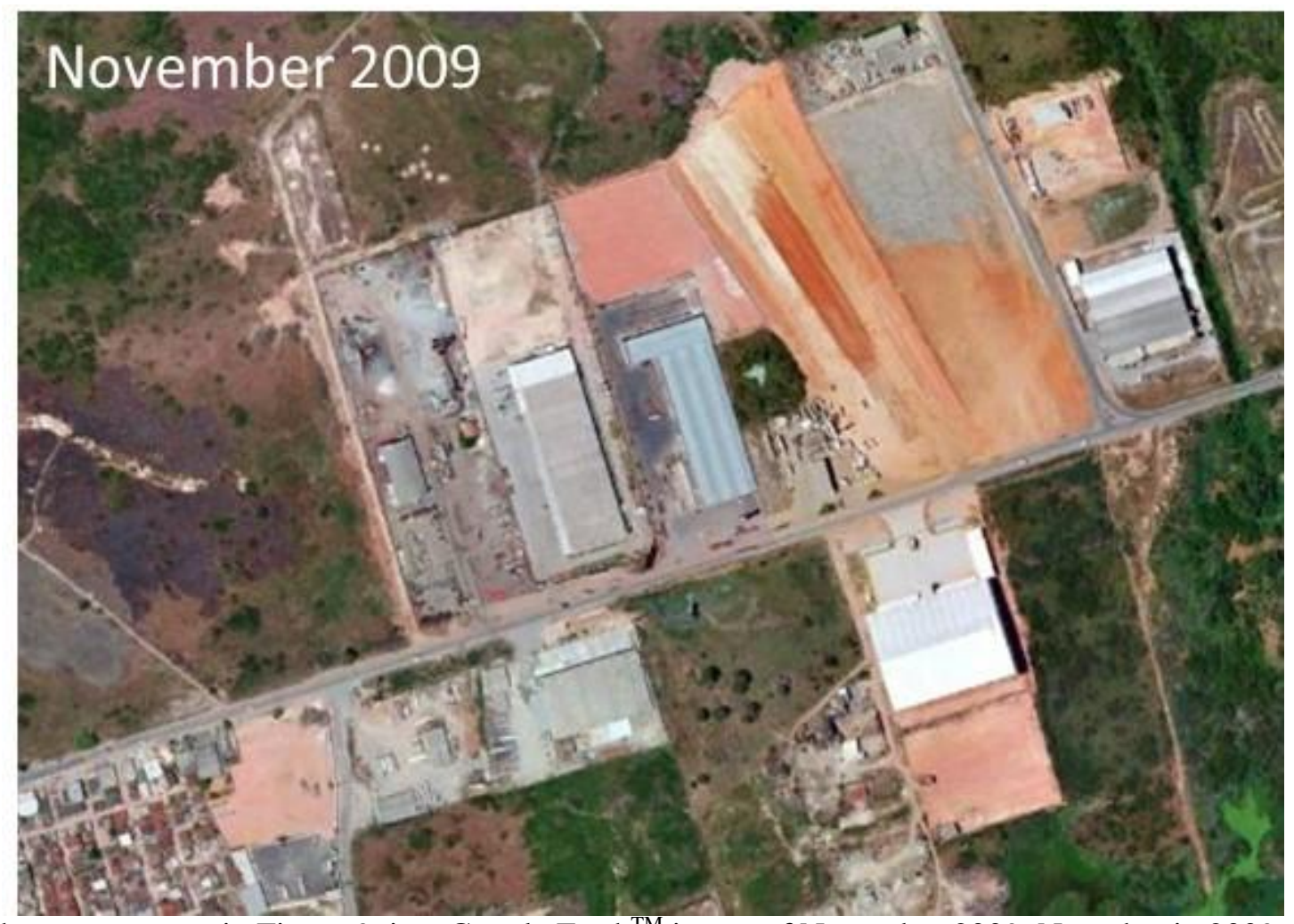

Figure 10- The same area as in Figure 9, in a Google Earth ${ }^{\mathrm{TM}}$ image of November 2009. Note that in 2009 the area is in development and the buildings showing ground settlement in Figure 9 are still in construction. 


\section{Conclusions}

This study used PSI analysis of 68 Sentinel-1 SLC images acquired in the time period April 2017 September 2019 to detect ground subsidence in the city of Recife. In the city of Recife it was noted a large ground subsidence area between the neighborhoods of Afogados, Torrŏes and Cordeiro. This ground subsidence with rates from few $\mathrm{mm}$ /year up to -15 $\mathrm{mm} /$ year could be related with groundwater extraction or with subsidence processes in rapidly urbanized lands due to the particular geology and soils of the area. Similar smaller ground subsidence zones occur in several localities in the Recife study area. In some cases the excessive sinking of the ground with rates up to $-25 \mathrm{~mm} /$ year occurs in small areas where new buildings have been constructed in the last ten years. This should be due to ground settlement processes, which take a longer time than usual due to particular soils and geology of the locality. This study can serve as a first contribution for further research on the ground subsidence hazard in the city of Recife by means of satellite radar imagery. Further monitoring of the ground subsidence in the city of Recife is necessary.

\section{References}

Bedini, E., 2019. Detection of ground subsidence in the city of Durrës, Albania, by Persistent Scatterer Interferometry of Sentinel-1 radar imagery. International Journal of Innovative Technology and Interdisciplinary Sciences 2, 297-306.

Budillon, A., Crosetto, M., Johnsy, A., Monserrat, O., Krishnakumar, V., Schirinzi, G., 2018. Comparison of persistent scatterer interferometry and SAR tomography using Sentinel-1 in urban environment. Remote Sensing 10, 1986.

Cabral, J.J.S.P., Farias, V.P., Sobral, M.D.C., Paiva, A.L.de, Santos, R.B., 2008. Groundwater management in Recife. Water International 33, 8699.

Chen, F., Lin, H., Zhang, Y., Lu, Z., 2012. Ground subsidence geo-hazards induced by rapid urbanization: Implications from InSAR observation and geological analysis. Natural Hazards and Earth System Sciences 12, 935-942.

Coelho, V.H.R., Bertrand, G.F., Montenegro, S.M., Paiva, A.L., Almeida, C.N., Galvão, C.O., Barbosa, L.R., Batista, L.F., Ferreira, E.L., 2018. Piezometric level and electrical conductivity spatiotemporal monitoring as an instrument to design further managed aquifer recharge strategies in a complex estuarial system under anthropogenic pressure.
Journal of Environmental Management 209, 426439.

Costa, W.D., Cabral, J.J.S.P., dos Santos, S.M., Costa Filho, W.D., 2005. O risco de uma subsidência no Recife. Estudos Geológicos 15, 90-101.

Costa W.D., Manoel Filho J., Santos A.C., Costa Filho W.D., Monteiro A.B., Sousa F.J.A., 1998. Groundwater exploitation zoning in Recife-PE. Congresso Brasileiro de Águas Subterrâneas, São Paulo.

Crosetto, M., Monserrat, O., Cuevas-González, M., Barra, A., Krishnakumar, V., Crippa, B., 2019. Urban deformation monitoring using Sentinel-1 SAR data: a case study. Joint International Symposium on Deformation Monitoring (JISDM), Athens.

Crosetto, M., Monserrat, O., Cuevas-González, M., Devanthéry, N., Crippa, B., 2016. Persistent scatterer interferometry: A review. ISPRS Journal of Photogrammetry and Remote Sensing 115, 7889.

Cui, Z.D., 2018. Land Subsidence Induced by the Engineering-Environmental Effect. Springer, Singapore.

Delgado Blasco, J.M., Foumelis, M., Stewart, C., Hooper, A., 2019. Measuring urban subsidence in the Rome metropolitan area (Italy) with Sentinel-1 SNAP-StaMPS persistent scatterer interferometry. Remote Sensing 11, 129.

Ferretti, A., Prati, C., Rocca, F., 2001. Permanent scatterers in SAR interferometry. IEEE Transactions in Geosciences and Remote Sensing 39, 8-20.

Hanssen, R.F., 2001. Radar Interferometry: data interpretation and error analysis. v. 2. Springer Science \& Business Media, Berlin.

Kalia, A., 2018. Classification of landslide activity on a regional scale using persistent scatterer interferometry at the Moselle Valley (Germany). Remote Sensing 10, 1880.

Lauknes, T.R., Shanker, A.P., Dehls, J.F., Zebker, H.A., Henderson, I.H.C., Larsen, Y., 2010. Detailed rockslide mapping in northern Norway with small baseline and persistent scatterer interferometric SAR time series methods. Remote Sensing of Environment 114, 2097-2109.

Luna, R.M.R.de, dos Anjos Garnés, S.J., Cabral, J.J.S.P., Santos, S.M.dos, 2017. Groundwater overexploitation and soil subsidence monitoring on Recife plain (Brazil). Natural Hazards 86, 13631376.

Notti, D., Mateos, R.M., Monserrat, O., Devanthéry, N., Peinado, T., Roldán, F.J., Fernández-Chacón, F., 
Galve, J.P., Lamas, F., Azañón, J.M., 2016. Lithological control of land subsidence induced by groundwater withdrawal in new urban areas (Granada Basin, SE Spain). Multiband DInSAR monitoring. Hydrological Processes 30, 2317-2331.

Sousa, J.J. and Bastos, L., 2013. Multi-temporal SAR interferometry reveals acceleration of bridge sinking before collapse. Natural Hazards and Earth System Sciences 13, 659-667.

Sowter, A., Amat, M.B.C., Cigna, F., Marsh, S., Athab, A., Alshammari, L., 2016. Mexico City land subsidence in 2014-2015 with Sentinel-1 IW TOPS: Results using the Intermittent SBAS (ISBAS) technique. International Journal of Applied Earth Observation and Geoinformation 52, 230-242.

Torres, R., Snoeij, P., Geudtner, D., Bibby, D., Davidson, M., Attema, E., Potin, P., Rommen, B., Floury, N., Brown, M., Traver, I.N., 2012. GMES
Sentinel-1 mission. Remote Sensing of Environment 120, 9-24.

Waltham, T., 2009. Foundations of Engineering Geology. Third edition. CRC Press, Boca Raton.

Yagüe-Martínez, N., Prats-Iraola, P., Gonzalez, F.R., Brcic, R., Shau, R., Geudtner, D., Eineder, M., Bamler, R., 2016. Interferometric processing of Sentinel-1 TOPS data. IEEE Transactions on Geoscience and Remote Sensing 54, 2220-2234.

Zan, F.de, Guarnieri, A.M., 2006. TOPSAR: Terrain observation by progressive scans. IEEE Transactions on Geoscience and Remote Sensing 44, 2352-2360.

Zhou, L., Guo, J., Hu, J., Li, J., Xu, Y., Pan, Y. and Shi, M., 2017. Wuhan surface subsidence analysis in 2015-2016 based on Sentinel-1a data by SBASInSAR. Remote Sensing 9, 982. 